\title{
Pengaruh Workplace Stretching Exercise (WSE) dan Heat Therapy (Hot Pack) terhadap Keluhan Muskuloskletal pada Perawat Tahun 2019
}

\author{
Eko Syafrianto', Pramana K. ${ }^{2}$, Zulfa $^{3}$ \\ ${ }^{1}$ Mahasiswa Program Studi Magister Keperawatan Universitas Andalas Padang \\ 2,3 Dosen Universitas Andalas Padang \\ Correspondence email: ekosyafrianto@yahoo.com
}

\begin{abstract}
Abstrak. Keluhan muskuloskeletal merupakan keluhan yang sering dirasakan perawat dalam memberikan asuhan keperawatan. Salah satu cara yang paling efektif untuk mengatasinya dengan pemberian terapi kombinasi workplace stretching exercise (WSE) dan heat therapy (hot pack). Tujuan penelitian ini adalah untuk mengetahui pengaruh WSE dan hot pack terhadap keluhan muskuloskeletal pada perawat. Penelitian ini merupakan penelitian Quasi Experiment Design dengan rancangan Two-Group PrePost. Sampel pada penelitian ini berjumlah 52 perawat yang dibagi menjadi 2 kelompok dengan menggunakan teknik simple random sampling. Keluhan muskuloskeletal diukur dengan menggunakan nordic body map (NBM). Analisis data menggunakan uji statistic Wilcoxon test pada tingkat kemaknaan 95\% dengan hasil uji (p.=0,000). Hal ini menunjukkan bahwa ada pengaruh WSE dan hot pack terhadap keluhan muskuloskeletal pada perawat. Perawat diharapkan lebih memperhatikan cara bekerja, beban kerja dan fasilitas kerja dengan baik serta melakukan WSE dan hot pack secara rutin.
\end{abstract}

Kata Kunci: Keluhan muskuloskeletal; Workplace Stretching Exercise; Heat Therapy (Hot Pack)

Abstract. Musculosceletal disorders are complaints that are often felt by nurses in providing nursing care. One of the most effective ways to overcome this is by providing combination therapy of workplace stretching exercise (WSE) and heat therapy (hot pack). The purpose of this study was to determine the effect of WSE and hot packs on musculosceletal disorders in nurses. This research is a Quasi Experiment Design study with a Two-Group Pre-Post design. The sample in this study were 52 nurses divided into 2 groups using simple random sampling technique. Musculosceletal disorders were measured using nordic body map (NBM). Data analysis used the Wilcoxon statistical and get at a significance level of $95 \%$ with test results $(p .=0,000)$. This shows that there is an influence of WSE and hot pack on musculosceletal disorders in nurses. Nurses are expected to pay more attention to how to work, workload and work facilities properly and do WSE and hot pack regularly..

Keywords: Musculosceletal disorders; Workplace Stretching-Exercise; Heat Therapy (Hot Pack)

\section{PENDAHULAN}

Perawat didalam memberikan tindakan keperawatan, sering kali tidak memperhatikan hal-hal penting yang menjadi faktor resiko terjadinya penyakit akibat kerja, terutama berkaitan dengan patient handling seperti tehnik mendorong/menarik, membawa, memutar, menahan, dan mengangkat/menurunkan pasien sering kali tidak dilakukan dalam keadaan yang benar sehingga banyak perawat yang mengalami keluhan muskuloskeletal. Keluhan muskuloskeletal adalah semua kondisi yang mempengaruhi saraf, tendon, otot dan struktur pendukung seperti cakram di punggung (IOSH, 2018). Keluhan muskuloskeletal yang dirasakan bisa ringan maupun sangat sakit, tergantung lama otot menerima beban statis secara berulang serta ada atau tidaknya kerusakan sendi, ligamen dan tendon (PSHSA, 2013). Banyak cara yang dapat dilakukan untuk mengurangi keluhan pada muskuloskeletal yaitu dengan termoterapi dan latihan peregangan (StretchingExercise) (Ali Satya Graha, 2009).

Termoterapi yang biasanya sering digunakan untuk mengurangi keluhan muskuloskeletal adalah heat therapy/terapi panas. Heat therapy (hot pack) merupakan terapi dengan menggunakan suhu panas dan dapat dipergunakan dengan kombinasi dengan terapi modalitas lainnya (Arovah, 2010). Heat therapy (hot pack) merupakan suatu intervensi terapeutik untuk menurunkan nyeri pada sendi dan otot serta jaringan lunak (Petrofsky, 2013). Heat therapy bekerja dengan meningkatkan sirkulasi dan aliran darah ke area tertentu karena peningkatan suhu sehingga dapat merilekskan, menenangkan otot dan menyembuhkan jaringan yang rusak (Judith, 2017). Penelitian Nurjanah (2016) menunjukan bahwa terapi panas efektif untuk mengurangi nyeri pada cedera otot hamstring.

Selain penggunaan heat therapy, Workplace Stretching-Exercise (WSE) juga dapat mengatasi keluhan muskuloskeletal. Workplace Stretching-Exercise merupakan suatu latihan peregangan yang telah didesain yang bisa dilakukan ditempat kerja untuk mengatasi keluhan musculoskeletal (Machado, 2012). Peregangan juga membantu meningkatkan semangat kerja, meningkatkan sirkulasi darah, fungsi fisik, serta fleksibilitas tubuh, sehingga mengurangi kemungkinan cedera dan keluhan muskuloskeletal (OSHC, 2015).

Berdasarkan penelitian Van Eerd et al (2016) menyimpulkan bahwa Stretching-Exercise adalah strategi yang paling efektif untuk mencegah dan merehabilitasi keluhan muskuloskeletal seperti nyeri leher, bahu dan punggung bawah. Berdasarkan hasil penelitian yang dilakukan oleh Lestari (2014) terhadap 54 perawat di bagian medical surgical, diperoleh hasil bahwa terdapat pengaruh dari stretching terhadap keluhan muskuloskeletal.

Rumah Sakit Umum Pusat Dr. M. Djamil Padang merupakan rumah sakit tipe A rujukan untuk Sumatera bagian tengah dan barat yang juga sebagai Rumah sakit pendidikan. Ruang rawat inap Bedah merupakan unit yang menangani kasus bedah dengan tindakan perawatan yang dilakukan cukup banyak dan dalam waktu cepat, meliputi gerakan mengangkat dan memindahkan pasien, membungkuk saat menangani pasien, serta melakukan gerakan yang tidak alamiah, yang apabila dilakukan berulang serta dalam ritme yang 
cepat dan tidak teratur menjadi salah satu faktor yang memengaruhi dan beresiko mengalami

Berdasarkan hasil wawancara dan observasi yang dilakukan peneliti terhadap 10 orang perawat di ruang kelas bedah dan CP didapatkan data $90 \%$ perawat mengalami keluhan muskuloskeletal. Dimana keluhan yang banyak terjadi pada pinggang dan leher. Perawat mengatakan nyeri terjadi saat mengangkat pasien yang berat, memindahkan pasien dari OK keruangan, memandikan pasien, membersihkan luka post op, luka bakar dan luka besar lainnya yang membutuhkan waktu yang lama. Hal ini jika tidak dilakukan pencegahan secepat mungkin akan menyebabkan kurang optimalnya asuhan keperawatan yang diberikan kepada pasien, resiko cidera pada perawat saat bekerja akan lebih besar serta dapat menurunkan produktifitas perawat dalam bekerja yang berujung berkurangnya pendapatan rumah sakit.

Berdasarkan latar belakang dan fenomena tersebut, peneliti ingin menggabungkan Heat therapy (hot pack) ini dengan Workplace Stretching-Exercise, yang mana Workplace Stretching-Exercise dipercaya dapat menurunkan keluhan pada muskuloskeletal. Maka dari itu peneliti tertarik untuk mengetahui seberapa besar pengaruh Workplace Stretching-Exercise (WSE) dan Heat therapy (hot pack) dalam menurunkan keluhan muskuloskeletal pada perawat di RSUP Dr. M. Djamil Padang.

\section{METODE PENELITIAN}

Penelitian ini merupakan penelitian Quasi Experiment Design dengan rancangan Two-Group PrePost. Sampel pada penelitian ini berjumlah 52 perawat yang dibagi menjadi 2 kelompok dengan menggunakan teknik simple random sampling, dimana kelompok 1 diberikan intervensi WSE dan hot pack dan kelompok kedua hanya diberikan intervensi hot pack Keluhan muskuloskeletal diukur dengan menggunakan Nordic Body Map (NBM). Analisis data menggunakan uji statistic Mann Whitney dan Wilcoxon test pada tingkat kemaknaan $95 \%$.

\section{HASIL DAN PEMBAHASAN}

Rumah Sakit Umum Pusat Dr. M. Djamil Padang merupakan rumah sakit tipe $A$ rujukan untuk Sumatera bagian tengah dan barat yang juga sebagai Rumah sakit pendidikan. RSUP Dr. M. Djamil Padang memiliki ruang rawat inap bedah yang terdiri dari 6 bagian yaitu kelas bedah, CAA, CP, RR, CW dan TC. Dimana karakteristik responden perawat sebagai berikut:

Tabel 1. Distribusi Karakteristik Perawat Berdasarkan Umur dan Lama Bekerja $(\mathrm{n}=52)$

\begin{tabular}{cccccc}
\hline Variabel & Jenis Kelompok & $\mathbf{n}$ & Median & SD & Min-Maxs \\
\hline Umur & Pertama & 26 & 30.5 & 10.159 & $24-55$ \\
& Kedua & 26 & 32.0 & 8.483 & $26-57$ \\
Lama bekerja (tahun) & Pertama & 26 & 5.0 & 10.766 & $1-33$ \\
& Kedua & 26 & 6.0 & 8.537 & $1-30$ \\
\hline
\end{tabular}

Hasil analisis menunjukkan bahwa rerata usia pada kelompok pertama adalah 30.50 tahun, usia termuda adalah 24 tahun dan tertua 55 tahun. Pada kelompok kedua rerata usia perawat 32 tahun, usia termuda adalah 26 tahun dan tertua 57 tahun. Rerata lama bekerja pada kelompok pertama adalah 5 tahun dan rerata lama bekerja pada kelompok kedua adalah 6 tahun

Tabel 2. Distribusi Karakteristik Perawat Berdasarkan Jenis Kelamin dan Tingkat Pendidikan ( $\mathrm{n}=52)$

\begin{tabular}{|c|c|c|c|c|c|c|}
\hline \multirow{2}{*}{ Karakteristik Responden } & \multicolumn{2}{|c|}{ Kelompok Pertama } & \multicolumn{2}{|c|}{ Kelompok Kedua } & \multicolumn{2}{|c|}{ Total } \\
\hline & $\mathbf{n}$ & $\%$ & $\mathbf{n}$ & $\%$ & $\mathbf{n}$ & $\%$ \\
\hline \multicolumn{7}{|l|}{ Jenis kelamin } \\
\hline Laki-laki & 5 & 19.2 & 4 & 15.4 & 9 & 100 \\
\hline Perempuan & 21 & 80.8 & 22 & 84.6 & 43 & 100 \\
\hline \multicolumn{7}{|l|}{ Pendidikan } \\
\hline D3 Kep & 20 & 76.9 & 21 & 80.8 & 41 & 100 \\
\hline S.1 Kep & 6 & 23.1 & 5 & 19.2 & 11 & 100 \\
\hline
\end{tabular}

Hasil analisis menunjukkan bahwa jenis kelamin pada kelompok pertama sebagian besar adalah perempuan sebanyak $80.8 \%$ dan pada kelompok kedua sebagian besar juga berjenis kelamin perempuan yaitu $84.6 \%$. Berdasarkan karakteristik tingkat pendidikan pada kelompok pertama sebagian besar tamatan D3 Keperawatan sebanyak $76.9 \%$ dan pada kelompok kedua sebagian besar juga tamatan D3 Keperawatan yaitu $80.8 \%$.

Tabel 3. Perbedaan Rerata Keluhan Muskuloskeletal pada Sebelum (Pretest) dan Sesudah (Posttest) Diberi Intervensi pada Kelompok Pertama dan Kedua $(n=52)$

\begin{tabular}{cccccccc}
\hline Kelompok & $\mathbf{n}$ & Median & Std. Deviation & Min & Max & $\mathbf{Z}$ & $\mathbf{p}$ \\
\hline Kelompok Pertama & & & & & & \\
Pretest & 26 & 33.00 & 2.401 & 30 & 39 & -4.469 \\
Posttest & 26 & 28.00 & 0.571 & 28 & 30 & 0.000 \\
Selisih pre-post & & 5.00 & 2.059 & - & - & \\
Kelompok Kedua & & & & 30 & 38 & \\
Pretest & 26 & 33.00 & 2.432 & 29 & 35 & -4.529 \\
Posttest & 26 & 31.00 & 1.745 & - & - & 0.000 \\
Selisih pre-post & & 2.00 & 1.148 & & \\
\hline
\end{tabular}


Dari table 3 menunjukkan rerata keluhan muskuloskeletal pada kelompok pertama sebelum dilakukan intervensi (pretest) adalah $33.00 \pm 2.401$ dan rerata keluhan muskuloskeletal sesudah dilakukan intervensi (posttest) adalah $28.00 \pm 0.571$. Hasil uji statistik menggunakan wilcoxon-test diperoleh $\mathrm{p}=0.000$ $(\alpha=0.05)$.

Rerata keluhan muskuloskeletal kelompok kedua sebelum dilakukan intervensi (pretest) adalah $33.00 \pm$ 2.432 dan rerata keluhan muskuloskeletal sesudah dilakukan intervensi (posttest) adalah $31.00 \pm 1.745$. Hasil uji statistik menggunakan wilcoxon-test diperoleh $\mathrm{p}$ $=0.000(\alpha=0.05)$,

\section{Pembahasan}

Hasil penelitian yang telah dilakukan peneliti didapatkan bahwa ada pengaruh workplace stretching exercise (WSE) dan heat therapy (hot pack) pada perawat, hal ini dapat dilihat pada tabel 3 menunjukkan reratakeluhan muskuloskeletal sebelum dilakukan intervensi (pretest) adalah $33.00 \pm 2.401$ dan rerata keluhan muskuloskeletal sesudah dilakukan intervensi (posttest) adalah $28.00 \pm 0.571$. Selisih penurunan rerata keluhan muskuloskeletal sebelum dilakukan intervensi (pretest) dan sesudah dilakukan intervensi (posttest) adalah 5.00. \pm 2.059 ,

Hasil uji statistic menggunakan wilcoxon-test diperoleh $p=0.000$ ( $\alpha=0.05)$, yang berarti $p$ lebih kecil dari $\alpha$, yang artinya secara statistik adalah Ha diterima dimana ada perbedaan rerata keluhan muskuloskeletal sebelum dilakukan intervensi (pretest) dan sesudah dilakukan intervensi (posttest) yang artinya bahwa ada pengaruh WSE dan hot pack terhadap keluhan muskuloskeletal pada perawat di RSUP Dr. M. Djamil Padang.

Hasil penelitian ini diperkuat dengan adanya kelompok kedua yang dijadikan perbandingan penurunan nilai keluhan muskuloskeletal antara kelompok yang diberi intervensi WSE dan hot pack dengan kelompok yang hanya diberi hot pack. dimana kelompok kedua yang hanya diberikan hot pack) juga mengalami penurunan tetapi tidak terlalu signifikan hal ini dapat dilihat pada tabel 5.4 menunjukkan rerata keluhan muskuloskeletal sebelum dilakukan intervensi (pretest) adalah $33.00 \pm 2.432$ dan rerata keluhan muskuloskeletal sesudah dilakukan intervensi (posttest) adalah 31.00. \pm 1.745. Selisih penurunan rerata keluhan muskuloskeletal sebelum dilakukan intervensi (pretest) dan sesudah dilakukan intervensi (posttest) adalah 2.00. \pm 1.148.

Workplace Stretching Exercise merupakan suatu kegiatan yang dianggap sebagai salah satu langkah yang digunakan untuk mengatasi keluhan muskuloskeletal, dan ditujukan untuk mencegah penyakit yang disebabkan oleh pekerjaan yang berulang dan membosankan serta mengurangi penyebab kecelakaan di tempat kerja dan masalah produktivitas yang rendah (Machado, 2012). Peregangan juga memberikan beberapa manfaat bagi orang-orang di tempat kerja seperti dapat membantu meningkatkan semangat kerja, dapat memperbaiki sirkulasi darah, meningkatkan fungsi fisik, meningkatkan fleksibilitas tubuh, sehingga mengurangi kemungkinan cedera dan keluhan muskuloskeletal (OSHC, 2015).

Manfaat kombinasi Workplace Stretching Exercise dan Heat therapy dalam berbagai intervensi yang dilakukan. Heat therapy merupakan terapi dengan menggunakan suhu panas dan dapat dipergunakan dengan kombinasi dengan terapi modalitas lainnya seperti Workplace Stretching Exercise (Arovah, 2010). Heat therapy bekerja hampir sama dengan cara kerja stretching yaitu dengan meningkatkan sirkulasi dan aliran darah ke area tertentu karena peningkatan suhu. Meningkatkan suhu area yang menderita bahkan dapat menenangkan ketidaknyamanan dan meningkatkan fleksibilitas otot. Terapi panas dapat merilekskan, menenangkan otot dan menyembuhkan jaringan yang rusak (Judith, 2017).

Besarnya penurunan keluhan muskuloskeletal pada perawat pada kelompok pertama yang diberi intervensi Workplace Stretching-Exercise (WSE) dan Heat therapy (hot pack) disebabkan karena latihan Workplace Stretching-Exercise (WSE) dapat merileksasi otot dan sendi serta memperlancar aliran darah disekitarnya sehingga membuat nyeri pada muskuloskeletal berkurang dan terapi ini sangat cocok di kombinasi dengan Heat therapy (hot pack) yang mana Heat therapy juga bekerja meningkatkan sirkulasi dan aliran darah ke area tertentu sehingga dapat menenangkan ketidaknyamanan dan meningkatkan fleksibilitas otot.

Pelaksanaan kombinasi Workplace Stretching Exercise dan Heat therapy dapat memberikan hasil yang efektif untuk berbagai intervensi keperawatan dibandingkan dengan penggunaan Heat therapy saja. Peneliti berharap untuk penelitian selanjutnya dapat menggali secara mendalam pengaruh Workplace Stretching Exercise dan Heat therapy terhadap keluhan muskuloskeletal dengan memperbanyak jumlah sampel serta melakukan penelitian lebih mendalam terkait keluhan muskuloskeletal yang terjadi pada perawat.

\section{SIMPULAN}

Hasil penelitian ini menunjukan ada pengaruh Workplace Stretching-Exercise (WSE) dan Heat Therapy (Hot Pack) terhadap keluhan muskuloskeletal pada perawat dan disarankan perawat di harapkan lebih memperhatikan cara bekerja, beban kerja dan fasilitas kerja dengan baik serta melakukan workplace sstretching exercise sebelum melakukan pekerjaan.

\section{DAFTAR PUSTAKA}

Achmadi, A \& Narbuko, C. (2013). Metodologi Penelitian. Jakarta : Bumi Aksara.

Alfara, I. (2017). Analisis Postur Kerja Operator Perakitan di Yessy Shoes untuk Mengidentifikasi Resiko Gangguan Muskuloskletal Akibat Kerja. Jurnal.Performa, https://jurnal.uns.ac.id/performa/article/ view/12742

Amalia, O. (2010). Analisis Faktor Risiko Muskuloskeletal Disorders (MSDs) pada Buruh Informal Pasar Grosir Blok F Tanah Abang Jakarta Pusat. UIN Syarif Hidayatullah Jakarta. 
http://repository.uinjkt.ac.id/dspace/handle $1123456789 / 3709$

Anderson, B. (2010). Stretching in The Office (Peregangan Untuk Orang Kantoran). Jakarta : Serambi IImu Semesta.

Anggraini, D.M., \& Saryono. (2013). Metodelogi Penelitian Kualitatif dan Kuantitatif Dalam Bidang Kesehatan. Yogyakarta : Nuha Medika.

Ardiansyah, A.A. (2011). Terapi Panas dan Dingin. Pontianak : Sekolah Tinggi Ilmu Keperawatan Muhammadiyah.

Arikunto, S. (2014). Prosedur Penelitian, Suatu Pendekatan Praktik. Jakarta : Rineka Cipta.

Arovah, N. I. (2010). Dasar-Dasar Fisioterapi Pada Cidera Olahraga. Yogyakarta: UMY.

Bridger, R.S. (2003). Introduction to Ergonomics, 2nd Ed. Tailor \& Francis Group. https://www.worldcat.org/title/introduction-toergonomics/oclc/538 79844

Budiono, S. (2009). Bunga Rampai Hiperkes \& Kk. Semarang: Universitas Diponegoro.

Bureau of Labor Statistics US Department of Labor. (2014). Nonfatal Occupational Injuries and Illnesses Requiring Days-Away-from-Work in 2014. Bureau of Labor Statistics US Department of Labor, 2014(202), 1-92. https://doi.org/USDL 15-2205

Cameron., Michele.,1999. Physical Agents in Rehabilitation; W.B.Saunders company, Philadelphia.

https://books.google.co.id/books?hl=id\&|r=\&id= IANuQ6pt6DUC\&oi=fnd\&pg=PP1\&dq=Cameron., +Michele.,1999.+Physical+Agents+in+Rehabilitati on\%3B+W.B.Saunders+company,+Philadelphia.\& ots=yW2HR4gMZa\&sig=HRSbpBwDQ46DTDqjQ 8h1DbVONc0\&redir_esc $=y \# v=$ onepage \& $q \& f=f a l s$ e

Cameron, M.H. (2013). Physical Agent in Rehabilitation. Elseiver. https://www.elsevier.com/books/physicalagents-in-rehabilitation/cameron/978-0-32344567-2

Canadian Centre for Occupational Health \& Safety Work-related. (2014). Musculoskeletal Disorders (WMSDs) - Risk Factors https://www.ccohs.ca/oshanswers/ergonomics /risk.html

Cherney K. (2013). Musculoskeletal Disorders. http://www.healthline.com/health /musculoskeletal-disorders

Crawford, J. O. (2007). The Nordic Muskuloskletal Questionnaire. Occopational Medicine Oxford Journal, 300-301. https://academic.oup.com/occmed/article /57/4/300/2751338

Dahlan. M. Sopiyudin. (2009). Statistik Untuk Kedokteran Dan Kesehatan. Jakarta : Salemba Medika.

De Carvalho, MVD., Soriano, EP., de Franca Caldas, A.Jr., Campello, R.I., de Miranda, H.F., Cavalcanti, F.I. (2009). Work-related musculoskeletal disorders among Brazilian dental students. J Dent Educ, 73(5): 624-630. http://www.ncbi.nlm.nih.gov/pubmed/19433537
Destiana, I. (2015). Hubungan Antara Tinggi dan Tipe Hak Sepatu Dengan Keluhan Nyeri Punggung Bawah Pada Pramuniaga di Departement Store X. Jurnal Kesehatan Masyarakat (E-Journal). https://ejournal3.undip.ac.id/ index.php/jkm/article/view/12311

Dewi, H.A.P. (2011). Peregangan Otot (Stretching): Rumah Sakit AZRA https://www.academia.edu/34526624/Latihan stre tching

Dickinson, C.E., Campion, K., \& Foster, A.F. (1992). Questionnaire Development: an examination of the Nordic Musculoskletal Questionnaire. Applied Ergonomics, (23), 197-201. https://www.sciencedirect.com/science /article/pii/000368709290225K

Dryastiti, P.E. (2013). Hubungan Antara Beban Kerja Dengan Tingkat Keluhan Muskulosletal Pada Perawat di Ruang Ratna dan Ruang Medical Surgical RSUP Sanglah Denpasar. Denpasar: Universitas Udayana

Elfering A, Mannion AF. (2008). Epidemiology and Risk Factors of Spinal Disorders. Spinal Disorders $E$ Fundamentals of Diagnosis and Treatment. Berlin (Germany): Springer http://medibone.cn/uploadfiles/book/20140109 /201401 09105257_2319.pdf

Employers Mutual Casualty. (2015). Stretching In The Workplace. Mulberry, Des Moines, USA. https://extest.emcins.com/lossControl/topicsIndust ries /warehousing.aspx

European Agency for Safety and Health at Work. (2013). New Risks and Trends In The Safety and Health of Women At Work. European Risk Observatory: Literature Review. European Agency for Safety and Health at Work (EU-OSHA). https://doi.org/10.2802/69206

Freitag, S., Ellegast, R., Dulon, M., \& Nienhaus, A. (2007). Quantitative Measurement Of Stressful Trunk Postures In Nursing Professions. Ann Occup Hyg. https://www.ncbi.nlm.nih.gov/pubmed/17715425

Graha, AS. (2009). Pedoman dan Modul Terapi Masase Frirage Penatalaksanaan Terapi Masase dan Cidera Olahraga Pada Lutut dan Engkel. Yogyakarta : Klinik Terapi Fisik UNY.

Guo, HR., dkk. (2004). Prevalence of Musculoskeletal Disorders Among Workers in Taiwan : A Nationwide Study. Journal of Occupational Health. https://www.ncbi.nlm.nih.gov/pubmed/14960827

Guyton, A.C., \& Hall, J.E. (2008). Buku Ajar Fisiologi Kedokteran Edisi 11. Jakarta : EGC.

Harcombe, H., McBride, D., Derrett, S., \& Gray, A. (2010). Physical and Psychosocial Risk Factors For Musculoskeletal Disorders In New Zealand Nurses, Postal Workers and Office Workers. http://dx.doi.org/10.1136/ip.2009.021766

Hasan, I. (2010). Analisis Data Penelitian Dengan Statistik. Jakarta : Bumi Aksara.

Health and Safety Executive. (2016). Health And Safety Statistic. UK. http://www.hse.gov.uk/statistics/

Hendra \& Rahardjo S. (2009). Risiko Ergonomi dan Keluhan Muskuloskeletal Disorders pada Pekerja 
Eko Syafrianto, et al, Pengaruh Workplace Stretching Exercise (WSE) dan Heat Therapy (Hot Pack) terhadap Keluhan Muskuloskletal pada

Panen Kelapa Sawit. Departemen Keselamatan dan Kesehatan kerja FKM UI. http://staff.ui.ac.id/system/files/users/dahen/ publication/d11.pdf

ILO. (2014). International Labour Organization. Decent Work Agenda, (34), 12-3. https://doi.org/10.1163/092735208X272247

Institution of Occupational Safety and Health (2018). Musculoskeletal Disorders. https://www.iosh.co.uk/books-and-resources/ouroh-toolkit/musculoskeletal-disorders.aspx

International Labour Organization. (2013). Keselamatan dan Kesehatan Kerja di Tempat Kerja Sarana untuk Produktivitas. Jakarta: ILO. https://www.ilo.org/jakarta/whatwedo/publications/ WCMS 237650/lang--en/index.htm

IOSH. (2018). Musculoskletal Disorders. Institution of Occupational Safety and Health The Grange, Highfield Drive, Wingston, Leicestershire, England. https://www.iosh.so.uk

Iridiastadi, H. (2007). Prevelence Of Muskuloskletal Symptoms Among Indonesia Workers : A Preliminary study. The Eight pan-pacific Conferance On Occupational Ergonomics. https://pdfs.semanticscholar.org/dd58/52ef2def 95bf291a190838e637dbea6959f0.pdf

John, L., \& Donald, M. (2007). Fire and Ice : The Great Debate on the Relative Value of Heat and Ice in Muskuloskletal Therapy. A Natarive review. Aus J Acupunt Med, 2(2).

Judith, MMD. (2017). Treating Pain with Heat and Cold. https://www.healthline.com/health/chronicpain/treating-pain-with-heat-and-cold

Kemenkes RI. (2014). Info Datin Pusat Data dan Informasi Kementerian Kesehatan RI. Kemenkes Rl, $\quad 109(1), \quad 1-8$. https://doi.org/10.1017/CBO9781107415324.004

Koesyanto, A. (2016). Pengaruh Stretching terhadap Nyeri Punggung Bawah dan Lingkup Gerak Sendi Pada Penyadap Getah Karet PT Perkebunan Nusantara IX (Persero). https://doi.org/10.15294/ujph.v5i1.9698

Koesyanto, H. (2013). Masa Kerja dan Sikap Kerja Duduk Terhadap Nyeri Punggung. Jurusan IImu Kesehatan Masyarakat Fakultas IImu Keolahragaan.

https://journal.unnes.ac.id/nju//index.php/kemas/ar ticle/view/ 2824

Laubli, T., \& Muller, C. (2009). Arbeitsbedingungen und Erkrankungen des Bewegungsapparates e geschatzte Fallzahlen und Kosten für die Schweiz. Bern,Switzerland: Eidgenossisches Volkswirtschaftsdepartement EDV. Staatssekretariat fur Wirtschaft SECO; [in German].

http://www.dievolkswirtschaft.ch/editions/200911/p $\mathrm{df} /$ Laeubli.pdf

Laurel, F. (2006). Heat \& Cold as Therapy. Toronto, Ontario, Canada : Curties-Overzet Publications Inc.

Lestari, N.L. (2014). Pengaruh Stretching Terhadap Keluhan Muskuloskeletal yang Dialami oleh Perawat di Ruang Ratna dan Medical Surgical
RSUP Sanglah. Universitas Udayana. https://ojs.unud.ac.id/index.php/coping /article/download/10766/7993/

Machado, JES., Seger, FC., Teixeira, CS., Pereira, EF., \& Merino, EAD. (2012). Queixas Musculoesqueleticas e a Pratica de Ginastica Laboral de Colaboradores de Instituicao Financeira. https://www.iosh.co.uk/Books-andresources/Our-OH-

Malonda, C. E., Kawatu, P. A., \& Doda, D. V. (2016). Gambaran Posisi Kerja Dan Keluhan Muskuloskeletal, 5(4), 267-272. https://ejournal.unsrat.ac.id/ index.php/pharmacon/article/download/14045/136 18

McFarlane, AC. (2007). Stress-Related Musculoskeletal Pain. Best Pract Res Clin Rheumatol. https://doi.org/10.1016/j.berh.2007.03.008

Morteza, D., \& Farinaz, F. (2014). The Efficacy of Thermotherapy and Cryotherapy. Journal of Clinical and Diagnostic Research, 8(9): LC01LC04.

https://dx.doi.org/10.7860\%2FJCDR\%2F2014\%2F 7404.4818

Muscolino, LE. (2009). The Muscle and Bone Palpation Manual With Trigger Points, Referral Patterns, And Stretching. Mosby, Inc., an affiliate of Elsevier Inc.

Notoatmodjo, S. (2012). Metodelogi Penelitian Kesehatan. Jakarta : Rineka Cipta.

Notoatmodjo, S. (2012). Promosi Kesehatan dan Perilaku Kesehatan. Jakarta: Rineka Cipta.

Nurjanah, S. (2016). Keefektifan Kombinasi Terapi Panas dan Dingin dengan Terapi Panas, Terapi Dingin Terhadap Cedera Otot Hamstring. Universitas Negeri Yogyakarta. http://journal.student.uny.ac.id/ojs/index.php/ikora /article/view/3675

Occupational Safety \& Health Council (OSHC). (2015). Workplace Stretching Exercises Relieve Stress. China United Centre. http://www.oshc.org.hk/eng/main/hot/stretching e xercise

OHSCO. (2007). Occupational Health and Safety Council of Ontario: Musculoskeletal Disorders Prevention Series. Resource Manual for the MSD Prevention Guideline for Ontario. https://www.iwh.on.ca/sites /iwh/files/iwh/tools/msd_prevention_ont_guideline 2007.pdf

O'Malley, G. (2011). Musculoskeletal Disorders in Obesity. Dalam F. Wilson, J. Gormley, dan J. Hussey, eds. Excercise Therapy ini the Management of Musculoskeletal Disorders. UK: Blackwell Publishing.

Oscar, M. (2012). Stretching Exercises Encyclopedia. Maidenhead: Meyer \& Meyer Sport (UK) Ltd.

OSHA. (2013a). Healthcare Wide Hazard Ergonomi. United State: Departemen of Labor United State. https://www.osha.gov/SLTC/ergonomics/control hazards .html

OSHA. (2013b). Occupational Safety and Health Guideline for Naphtha (Coal 
Tar).http://www.osha.gov/SLTC/healthguidelines/n aphthacoaltar/recognition.html

Permata, EG. (2016). Analisis Gangguan Muskuloskeletal Terhadap Perawat Berdasarkan Tingkat Paparan dengan Menggunakan Metode Movement and Assistance of Hospital Patient Index. Jurnal Teknik Industri 2(1). http://ejournal.uinsuska.ac.id/index.php/iti/article/view/5063

Peter, VI. (2004). Musculoskeletal Disorders. London: Taylor and Francis.

Petrofsky, J., Berk, L., \& Lee, H. (2013). Moist Heat or Dry Heat Delayed Onset Muscle Soreness. Journal of Clinical Medicine Research, $2 B$. https://doi.org/10.4021/jocmr1521w

Prentice, WE. (2008). Arnheim's Principles of Athletic Training: a Competency Based Approach. New York: McGraw-Hill.

PSHSA. (2013). Musculoskeletal disorders. https://www.pshsa.ca/wpcontent/uploads/2013/01/MSDs.pdf

Rovitri, A. (2015). Perbedaan Keluhan Muskuloskeletal Sebelum dan Sesudah Workplace StretchingExercise (WSE) Pada Petugas Perawat di Rumah Sakit lbu dan Anak (RSIA) Badrul Aini. https://jurnal.usu.ac.id/index. $\mathrm{php} / \mathrm{lkk} /$ article/view/10784

RSUP Dr. M. Djamil Padang. (2018). Profil RSUP DR. M. Djamil Padang. Padang.

Rusni, NW. (2017). Workplace Stretching Exercise dan Pemberian Teh Manis Memperbaiki Respon Fisiologis dan Meningkatkan Produktivitas Penjahit di PT. Fussion Hawai. The Indonesia Journal of Ergonomic, Vol.3. https://ojs.unud.ac.id/index.php/jei/article/downloa d/32603/19735/

Santos, AC., Bredemeier, M., Rosa, KF., Amantea, VA., \& Xavier, RM. ( 2011). Impact on the Quality of Life of an Educational Program for the Prevention of Work-Related Musculoskeletal Disorders: a Randomized Controlled Trial. BMC Public Health. https://doi.org/10.1186/1471-2458-11-60

Schneider, E., \& Irastorza, X. (2010). Work-related musculoskeletal disorders in the EU-Facts and Figures. European Agency for Safety and Health at

Work.

https://osha.europa.eu/en/tools/andpublications/pu blications/reports/TERO09009ENC/view

Scott F. Nadler, et al. (2004). The Physiologic Basic and Clinical Application of Cryotherapy and Thermotherapy for the Pain Practitioner. Pain Physician,

7(3).

http://www.preventworkinjury.com/wpcontent/uploads/2014 /10/Heat-vs-ColdTherapy.pdf

Siqueira, ACA., \& Couto, MT. (2013). As LER/DORT no contexto do encontro simbolico entre pacientes e medicos peritos do INSS/SP. Saude Soc, 22(3). http://dx.doi.org/10.1590/S010412902013000300006

Silverstein, B., \& Evanoff, B. (2006). Musculoskeletal Disorders. Dalam B. S. Levy et al., eds. Occupational and Environmental Health:
Recognizing and Preventing Disease and Injury. USA: Lippincott Williams dan Wilkins.

Simkin, P. (2007). Panduan Lengkap Kehamilan Melahirkan \& Bayi. Jakarta : Archan.

Smeltzer \& Bare (2013). Buku Ajar Keperawatan Medical Bedah Bruner \& Suddarth Edisi 8. Jakarta : EGC.

Soedirman, S. (2014). Keselamatan dan Kesehatan Kerja. Yogyakarta: Gosyen Publishing.

Sudianingrum, AW. (2016). Perbedaan Pengaruh William Flexion Exercise dan Infrared dengan Low Back Exercice dan Infrared Terhadap Aktivitas Fungsional Trunk Pada Work Related Back Pain. Universitas Aisyiyah Yogyakarta. http://digilib.unisayogya.ac.id/2124/1/NASKAH\%2 OPUBLIKA

SI\%20Anggi\%20Wahyu\%20Sudianingrum.pdf

Sugiyono. (2015). Metode Penelitian Kuantitatif, Kualitatif dan $R \& D$. Bandung: Alfabeta.

Su'mamur, P.K. (2009). Higiene Perusahaan dan Kesehatan Kerja. Jakarta: Sagung Seto.

Suriyatmini, S. (2010). Tinjauan Faktor Risiko Ergonomi Terhadap keluhan Muskuloskeletal pada Aktivitas Manual Handling pada Pekerja di Bagian Produksi PTMI Tahun 2010. Tesis. Fakultas Kesehatan Masyarakat, Universitas Indonesia, Depok. http://lib.ui.ac.id/file?file=digital/20225832-T28881Tinjauan\%20faktor.pdf

Tarwaka, dkk. (2004). Ergonomi Untuk Keselamatan Kesehatan Kerja dan Produktivitas. Surakarta: UNIBA.

Tarwaka, H. (2015). Ergonomi Industri Dasar-Dasar Pengetahuan Ergonomi dan Aplikasi di Tempat Kerja Edisi II. Surakarta: Harapan Press.

Trinkoff, AM., Brady, B., \& Nielsen, K. (2003). Workplace Prevention And Musculoskeletal Injuries in Nurses. J Nurs Adm. https://www.ncbi.nlm. nih.gov/pubmed/12629302

University of Toronto Environment Health And Safety. (2015). Workplace Exercise. https://www.ehs.utoronto.c/services/ergonomi/exe rcise.htm

Van Eerd, D.,et al. (2016). Effectiveness of Workplace Interventions in The Prevention of Upper Extremity Musculoskeletal Disorders and Symptoms: An Update Of The Evidence. Occup. Environ. Med. 73, 62-70. http://dx.doi.org/10.1136/oemed--102992.

Yuswanto, TJ. (2012). Pengaruh Kompres Hangat Terhadap Penurunan Intensitas Nyeri Pinggang Bawah. http://elibrary.ub.ac.id

Zulfiqor, MT. (2010). Faktor-faktor yang Berhubungan dengan Keluhan Muskuloskeletal Disorders pada Welder dibagian Fabrikasi PT CATERPILLAR INDONESIA. Universitas Islam Negeri Syarif Hidayatullah. Jakarta. http://digilib.unhas.ac.id/uploaded_files/temporary/ DigitalCollection/NGRjNDBjMDNiYTTVjNGNIMDN mNzEwZDE1OWE5MzgwMDg4NjVkYTU5NA==.p df 